\title{
TMEM263: a novel candidate gene implicated in human autosomal recessive severe lethal skeletal dysplasia
}

\author{
Mahsa Sadat Asl Mohajeri ${ }^{1}$, Atieh Eslahi ${ }^{1,2,3}$, Zeinab Khazaii ${ }^{4}$, Mohammad Reza Moradi ${ }^{1}$, Reza Pazhoomand ${ }^{5,6}$, \\ Shima Farrokhi ${ }^{1,3}$, Masoumeh Heidari Feizabadi ${ }^{1}$, Farzaneh Alizadeh ${ }^{1}$ and Majid Mojarrad ${ }^{1,3,4^{*}}$ (i)
}

\begin{abstract}
Introduction: Skeletal dysplasia is a common, clinically and genetically heterogeneous disorder in the human population. An increasing number of different genes are being identified causing this disorder. We used whole exome sequencing (WES) for detection of skeletal dysplasia causing mutation in a fetus affected to severe lethal skeletal dysplasia.

Patient: Fetus was assessed by ultrasonography in second trimester of pregnancy. He suffers from severe rhizomelic dysplasia and also pathologic shortening of ribs. WES was applied to finding of causal mutation. Furthermore, bioinformatics analysis was performed to predict mutation impact.

Results: Whole exome sequencing (WES) identified a homozygous frameshift mutation in the TMEM263 gene in a fetus with severe lethal skeletal dysplasia. Mutations of this gene have been previously identified in dwarf chickens, but this is the first report of involvement of this gene in human skeletal dysplasia. This gene plays a key role in the growth hormone signaling pathway.

Conclusion: TMEM263 can be considered as a new gene responsible for skeletal dysplasia. Given the complications observed in the affected fetus, the mutation of this gene appears to produce much more intense complications than that found in chickens and is likely to play a more important role in bone development in human.
\end{abstract}

Keywords: Skeletal dysplasia, Novel gene, Whole exome sequencing, Gene discovery

\section{Introduction}

Skeletal dysplasia is a common and heterogeneous developmental disorder, with more than 450 different disorders, associated with impaired longitudinal growth and bone mineralization. The disorder affects one in every 5000 live births, approximately [1].

Various environmental, teratogenic, and genetic factors are involved in causing this complication. Genetic

\footnotetext{
* Correspondence: majidmojarrad@gmail.com

'Department of Medical Genetics, Faculty of Medicine, Mashhad University of Medical Sciences, Mashhad, Iran

${ }^{3}$ Medical Genetics Research Center, Faculty of Medicine, Mashhad University of Medical Sciences, Mashhad, Iran

Full list of author information is available at the end of the article
}

factors play an important role in causing bone dysplasia and so far mutations in 226 different genes have been reported in patients with skeletal dysplasia [1].

Although the genetic cause of an increasing number of skeletal dysplasia syndromes is being discovered, the genetic etiology of many of these disorders remains unknown.

It is important to identify the genetic causes of skeletal dysplasia in genetic counseling, prenatal diagnosis, and prognosis of the patient.

The TMEM263 gene has recently been identified as one of the causes of autosomal recessive dwarfism in Cornell K-strain white leghorns [2]. Mutation of this gene results in short stature and weight loss despite

C C The Author(s). 2021 Open Access This article is licensed under a Creative Commons Attribution 4.0 International License, which permits use, sharing, adaptation, distribution and reproduction in any medium or format, as long as you give appropriate credit to the original author(s) and the source, provide a link to the Creative Commons licence, and indicate if changes were made. The images or other third party material in this article are included in the article's Creative Commons licence, unless indicated otherwise in a credit line to the material. If material is not included in the article's Creative Commons licence and your intended use is not permitted by statutory regulation or exceeds the permitted use, you will need to obtain permission directly from the copyright holder. To view a copy of this licence, visit http://creativecommons.org/licenses/by/4.0/ The Creative Commons Public Domain Dedication waiver (http://creativecommons.org/publicdomain/zero/1.0/) applies to the data made available in this article, unless otherwise stated in a credit line to the data. 
normal levels of growth hormone and insulin-like factor 1 [3].

Interestingly, although no association has been observed with skeletal dysplasia so far, some GWAS studies have shown a significant association between TMEM263 genetic variants and bone mineral density (BMD) and bone fracture risk in humans [4].

In addition, bioinformatics studies of transcriptome data have shown concurrent expression of this gene and osteoblast functional modules (OFMs) [5].

In the present study, we identified for the first time the TMEM263 mutation in a fetus suffering bone skeletal dysplasia using WES technology and investigating autologous gene recognized in dwarf chicken.

\section{Patient and methods \\ Clinical brief}

A consanguineous couple with a fetus with fatal skeletal dysplasia was referred for genetic counseling before termination of pregnancy. In the initial study, couples had a previous pregnancy with the same problem (Fig. 1).

The couple underwent genetic counseling and ultrasound examination of the fetus. Amniocentesis was performed to culture of amniotic fluid cells.

The sample was a male aborted fetus. Fetal age at diagnosis was 15 week and 1 day based on first trimester indices, 16 weeks based on biparietal diameter ) BPD(, and 16 weeks and 1 day based on abdominal circumference ) $\mathrm{AC}$ ( and the fetal weight was $85 \mathrm{~g}$.

The fetal femur length was $6.5 \mathrm{~mm}$ (lower than 2.5th percentile of the normal population).
On ultrasonography examination, humerus length was $2 \mathrm{~mm}$ (lower than 5th percentile of the normal population) and tibial bone length was $1 \mathrm{~mm}$ (lower than 2th percentile of the normal population). Pathological shortening of ribs and other long bones was evident.

Furthermore, bilateral clubfoot and clubhand was apparent.

There was no evidence of cleft palate and lip. Gastric bubble, kidneys, and bladder appeared normal.

In color Doppler study, normal cord with two arteries and one vein was observed.

No abnormalities were observed in CNS examination and lateral ventricle diameter was within normal range.

Nuchal fold was in pathological range $(5.7 \mathrm{~mm})$ and nasal bone length was lower than 2.5 th percentile of the normal population.

Doppler examination of fetal heart showed quadruple and triceps view and no pathologic findings.

Finally, according to these evidences, diagnosis of severe lethal micromelia was confirmed. Termination of pregnancy was performed under the supervision of a gynecologist.

In family history, similar findings were apparent in previous pregnancy. In addition, previous fetus shows several angulations suspected to fracture has been detected and interestingly, omphalocele has been detected in former fetus but not in later one.

Whole exome sequencing and segregation analysis After taking informed consent from parents, the WES assay was performed according to standard protocol. In brief, genomic DNA samples were extracted from

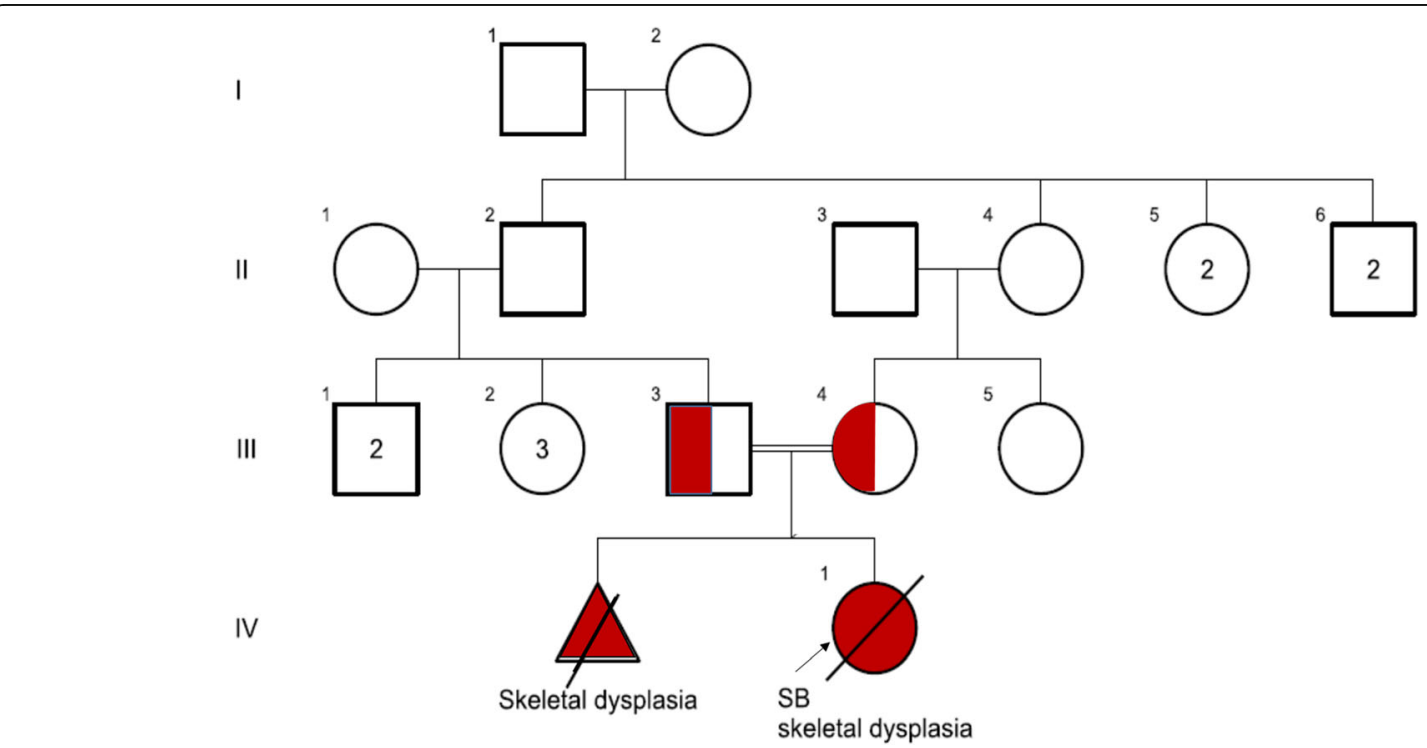

Fig. 1 Family pedigree. Filled red symbols indicate members affected with skeletal dysplasia and half-filled shows heterozygote for the mutation and the proband is indicated with the arrow 
cultured amniotic cells using DNA extraction kit (SIMBIOLAB, IRAN).

The whole exome captured using the Agilent SureSelect Target Enrichment Kit preparation guide. The libraries were sequenced with Illumina HiSeq 2000/2500 sequencer.

Reads were Mapped hg19 human reference genome assembly and cleaned to using BWA and Samtools, respectively [6, 7]. Duplicated reads were removed by using Samtools dedup function. Variant filtering was performed toward the SNPs and indels using VarScan v2.3.9, can generally run from 3 to 25 budgets [8]. Functional annotation for detected variants was performed using Wannovar [9].

Known skeletal dysplasia causing genes were extracted. Filtering of variants was done using multiple steps based on homozygosity status, allelic frequencies in different population databases, mutation impact on gene function, and mutation effect based on various prediction databases.

In next step, other preferred variants based on above algorithm were studied based on PubMed literature.

Sequence analysis was performed using the Sanger sequencing method to confirmation of TMEM263 candidate gene variant. Primers sequences are listed in Table 1.

Polyphen, LIF, SIFT, MUTATION TASTER, PROVEAN softwares were used to predict the identified variant effects. The domain information of TMEM263 gene was obtained from pfam and interpro databases.

\section{Results}

In the WES study, 123011 variant with an average depth of $50 \times$ and minimum depth of $8 \times$ was detected. 6254 SNPs and indels variants belong to known skeletal dysplasia causing genes were extracted, all of which were either intronic or common population polymorphisms greater than $2 \%$.

In the second step, variant filtering was performed based on previously mentioned criteria.

Interestingly, a new variant was observed in the TMEM263 gene. This mutation is located in exon 4 of the gene, resulting in the deletion of 188-189th nucleotides, resulting in a shift of the reading frame from amino acid lysine number 63 onwards resulting in the creation of a premature stop codon in the 68th residue.

This variant was not reported in the 1000G, ExAC, gnomAD, and also Iranome. Furthermore, this mutation was not observed in our local database, which contained
400 WES data from the eastern part of Iran. So, this variant is a family specific mutation which may lead to this phenotype.

Polyphen, LIF, SIFT, MUTATION TASTER, PROVEAN softwares detect the identified mutation as either deleterious or possibly damaging or pathogenic.

Examination of the protein sequence from the mutation revealed the elimination of the majority of the second trans-membrane domain of protein which by eliminating that the function of this protein is virtually lost.

In addition, this mutation may also result to nonsense mediated mRNA decay (NMD), which would completely silence TMEM263 protein expression. Sequence analysis showed heterozygous status in both parents (Fig. 2).

\section{Discussion}

In this study, using WES, we have identified TMEM263 mutation as a new severe lethal skeletal dysplasia causative mutation. This gene is located on chromosome $12 q 23.3$ and contains 4 exons, which only exons 3 and 4 are encoding, producing a protein of 116 amino acids in length.

Few studies have been performed on TMEM263 gene and the physiological role of this gene remains largely unknown. However, the study of $\mathrm{Wu}$ et al. has shown that TMEM263 protein is highly conserved among all vertebrates [2]. This protection is particularly apparent in the two trans-membrane domains (units 38 to 61 equivalent to the first domain and 80 to 102 units to the second domain). In human TMEM263 protein, the two domains comprise the first domain 40-60 and the second domain subunit 98-78.

TMEM263 is expressed in a wide range of tissues at different stages of development and has the highest expression level in tibia. Interestingly, the expression of this gene in tibia in the samples of individuals 6 to 12 years is higher than in adults.

A nonsense mutation detected in the Trp59 residue in the dwarf Cornell K-strain white leghorns results in the deletion of the second domain of the protein, resulting in the protein completely losing its function. Interestingly, our mutation occurred in Lysine 63, leading to the early termination of the protein [2].

TMEM263 directly interacts with GH1 and BMP2, both of which are essential for the normal growth and development of long bones [2]. In addition, based on the data obtained from GeneMANIA, the protein TMEM263 also

Table 1 Primer sequence of TMEM263 mutation confirmation

\begin{tabular}{llll}
\hline Primer name & Sequence $\left(\mathbf{5}^{\prime}\right.$ to $\left.\mathbf{3}^{\prime}\right)$ & Tm & Amplification product length \\
\hline TMEM263F & GAAAGATCACCCACAGCAG & 52.63 & 237 bp \\
TMEM263R & TTACAACAGCAGACCCAAC & 45.00 & \\
\hline
\end{tabular}




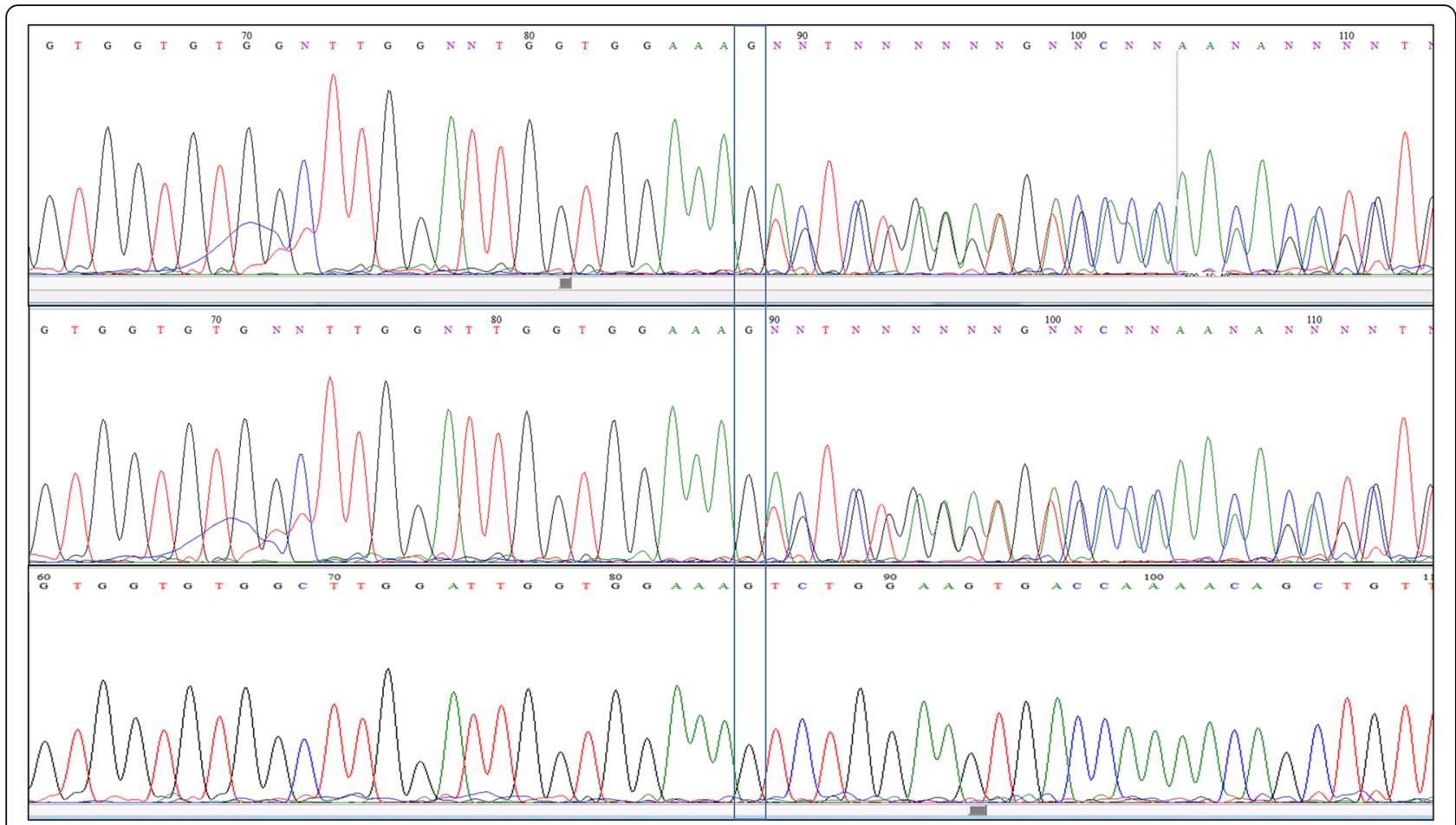

Fig. 2 Partial sequence chromatogram displaying the DNA sequence of parents. The arrowhead indicates the position of the homozygous onenucleotide deletion (c.188_189delAG) resulting in a frameshift mutation

coexpressed with FAM3C and RBPJ proteins. These genes have known effects on osteogenesis and bone density in humans [10-12].

Recent GWAS studies also show a significant association of TMEM263 variants with bone mineral density in humans $[4,13]$.

On the other hand, co-immunopercipitation studies on the Slick protein, a sodium-activated potassium channel, indicate physical binding of this protein to TMEM263 [14]. Because dysfunction of the Slick gene leads to infantile epileptic encephalopathy type 57, TMEM263 gene dysfunction may also be involved in genetic disorders of the nervous system and epilepsy syndromes [15]. However, the lack of neurological effects in the animal model of this mutation suggests that this gene may not play a critical role in the central nervous system.

Another important point is that the consequences of this mutation in the human fetus appear to be much more severe than the complications of the chicken, suggesting a higher physiological importance of this gene in humans than in the chicken.

\section{Conclusion}

In this study, we identified TMEM262 as a novel gene involving in skeletal dysplasia. This finding can be used to screening of patients with skeletal dysplasia.
Acknowledgements

We thank all collaborators for providing detailed clinical data and samples to conduct this study.

\section{Authors' contributions}

Atieh Eslahi and Majid Mojarrad: Data analysis. Zaynab Khazaeii and Reza Pazhoomand: Patient history. Mahsa Sadat Asl Mohajeri and Masumeh Heidari Feizabadi: Article editing. Farzaneh Alizadeh and Shima Farrokhi: Article writing. The authors read and approved the final manuscript.

Funding

Not applicable.

Availability of data and materials

Mentioned in the text.

\section{Declarations}

Ethics approval and consent to participate Not applicable.

\section{Consent for publication}

Not applicable.

\section{Competing interests}

The authors declare that they have no competing interests.

\section{Author details}

'Department of Medical Genetics, Faculty of Medicine, Mashhad University of Medical Sciences, Mashhad, Iran. ${ }^{2}$ Student Research Committee, Faculty of Medicine, Mashhad University of Medical Sciences, Mashhad, Iran. ${ }^{3}$ Medical Genetics Research Center, Faculty of Medicine, Mashhad University of Medical Sciences, Mashhad, Iran. ${ }^{4}$ Genetic Center of Khorasan Razavi، Mashhad, Iran. ${ }^{5}$ Legal Medicine Research Center, Legal Medicine Organization of Iran, Tehran, Iran. ${ }^{6}$ Genetic Department, Shiraz Fertility Center, Shiraz, Iran. 
Received: 28 January 2021 Accepted: 21 June 2021

Published online: 08 July 2021

\section{References}

1. Warman ML, Cormier-Daire V Fau - Hall C, Hall C Fau - Krakow D, Krakow D Fau - Lachman R, Lachman R Fau - LeMerrer M, LeMerrer M Fau - Mortier G, et al. Nosology and classification of genetic skeletal disorders: 2010 revision. (1552-4833 (Electronic)). eng.

2. Wu Z, Derks MFL, Dibbits B, Megens HJ, Groenen MAM, Crooijmans R. A novel loss-of-function variant in transmembrane protein 263 (TMEM263) of autosomal dwarfism in chicken. Front Genet. 2018;9:193 PubMed PMID: 29930570. Pubmed Central PMCID: 6001002.

3. Cole RK. An autosomal dwarfism in the domestic fowl. (0032-5791 (Print)). eng.

4. Estrada K, Styrkarsdottir U, Evangelou E, Hsu YH, Duncan EL, Ntzani EE, et al. Genome-wide meta-analysis identifies 56 bone mineral density loci and reveals 14 loci associated with risk of fracture. Nat Genet. 2012;44(5):491501 PubMed PMID: 22504420. Pubmed Central PMCID: 3338864.

5. Calabrese GM, Mesner LD, Stains JP, Tommasini SM, Horowitz MC, Rosen CJ, et al. Integrating GWAS and co-expression network data identifies bone mineral density genes SPTBN1 and MARK3 and an osteoblast functional module. Cell Syst. 2017:4(1):46-59 e4. PubMed PMID: 27866947. Pubmed Central PMCID: 5269473.

6. Li H, Durbin R. Fast and accurate short read alignment with BurrowsWheeler transform. (1367-4811 (Electronic)). eng.

7. $\quad$ Li H, Handsaker B Fau - Wysoker A, Wysoker A Fau - Fennell T, Fennell T Fau Ruan J, Ruan J Fau - Homer N, Homer N Fau - Marth G, et al. The sequence alignment/map format and SAMtools. (1367-4811 (Electronic)). eng.

8. Koboldt DC, Zhang Q Fau - Larson DE, Larson De Fau - Shen D, Shen D Fau - McLellan MD, McLellan Md Fau - Lin L, Lin L Fau - Miller CA, et al. VarScan 2: somatic mutation and copy number alteration discovery in cancer by exome sequencing. (1549-5469 (Electronic)). eng.

9. Chang X, Wang K. WANNOVAR: annotating genetic variants for personal genomes via the web. (1468-6244 (Electronic)). eng.

10. Bendre A, Buki KG, Maatta JA. Fam3c modulates osteogenic differentiation by down-regulating Runx2. (1432-0436 (Electronic)). eng.

11. Zhao B, Miller CA-O, Smith SA-O, Elguindy M, Zhang TA-OX, Xiang JZ, et al, TNF and bone remodeling RBP-J-regulated miR-182 promotes TNF-alphainduced osteoclastogenesis. (1544-2241 (Electronic)). eng.

12. Miller CA-O, Smith SA-O, Elguindy M, Zhang TA-OX, Xiang JZ, Hu XA-O, et al. RBP-J-Regulated miR-182 promotes TNF-alpha-induced osteoclastogenesis. (1550-6606 (Electronic)). eng.

13. Mitchell JA, Chesi A, Elci O, McCormack SE, Kalkwarf HJ, Lappe JM, et al. Genetics of bone mass in childhood and adolescence: effects of sex and maturation interactions. J Bone Mineral Res. 2015;30(9):1676-83 PubMed PMID: 25762182. Pubmed Central PMCID: 4839534

14. Rizzi S, Schwarzer C, Kremser L, Lindner HH, Knaus HG. Identification of potential novel interaction partners of the sodium-activated potassium channels Slick and Slack in mouse brain. (2405-5808 (Electronic)). eng.

15. Gururaj S, Palmer EE, Sheehan GD, Kandula T, Macintosh R, Ying K, et al. A de novo mutation in the sodium-activated potassium channel KCNT2 alters ion selectivity and causes epileptic encephalopathy. (2211-1247 (Electronic)). eng.

\section{Publisher's Note}

Springer Nature remains neutral with regard to jurisdictional claims in published maps and institutional affiliations.

Ready to submit your research? Choose BMC and benefit from:
- fast, convenient online submission
- thorough peer review by experienced researchers in your field
- rapid publication on acceptance
- support for research data, including large and complex data types
- gold Open Access which fosters wider collaboration and increased citations
- maximum visibility for your research: over 100M website views per year
At BMC, research is always in progress.
Learn more biomedcentral.com/submissions

